\title{
ACTIVELY DEMONSTRATING LIBRARY EXPERTISE IN A RESEARCH ASSESSMENT EXERCISE
}

\section{Authors:}

Gabrielle K. W. Wong, Victoria F. Caplan, Diana L. H. Chan, Lois M. Y. Fung, K. T. Lam

Recent studies have shown that researchers in universities in both the USA and the UK often do not highly value institutionally provided research services (MacColl \& Jubb, 2011). Less than $60 \%$ of US faculty in a recent survey considered the Library's role in providing active support to increase their research productivity important, with only about $40 \%$ of STEM faculty finding it so. (Housewright, et al., 2012). Some reports conclude that libraries can raise their profiles and value to their institutions through their work during national research assessments (Key Perspectives Ltd. for OCLC Research, 2009; Haddow, 2012).

At the Hong Kong University of Science and Technology (HKUST), the Library's experience at preparing data for the 2014 Research Assessment Exercise (RAE 2014) demonstrated how this could be achieved. To assist the university in the data submission process for this high-stake exercise, the Library built on its expertise with research information management, and engaged deeply with the government assessment body and the university's administration. Similar to other national research assessments, the RAEs in Hong Kong are large-scale and highly complex. Eight higher education institutions with a large number of researchers in different disciplines are involved. RAE 2014 is a particularly interesting case. The government assessment body-the University Grants Committee (UGC) decided to adopt electronic means for this round. As to how the electronic infrastructure was to be constructed, the UGC involved all institutions early on. This turned out to be a major challenge and also an interesting opportunity for libraries in these institutions.

This paper describes how the HKUST Library actively participated in this highly complex project, tactfully handled many challenges; and as a result demonstrated library's value and librarians' expertise in supporting university research. 


\section{About Hong Kong's RAE 2014}

The University Grants Committee of Hong Kong (UGC) advises the Hong Kong Government on the development and funding needs of its higher education institutions. It is the major funding source for public universities in Hong Kong. Currently there are eight higher institutions funded by the UGC.

The UGC conducted four RAEs in 1993, 1996, 2006, and recently 2014. The results of RAEs link to future funding. These exercises were modelled on the UK system. The UGC began to prepare the work of RAE 2014 in 2011. The operation for RAE 2014 was very different from the previous exercises as it required for the first time data submission in electronic format. In previous RAEs, researchers and institutions submitted paper copies of documents. Boxes of papers were assembled at individual institutions, shipped to the UGC for distribution to local and overseas reviewers. This involved a large volume of manual labor. Hence, the UGC decided to transform the RAE 2014 into an electronic process, from document submission, file storage, to seamless access to the documents by local and overseas reviewers. This requirement would involve a robust electronic system and a completely new submission workflow.

\section{Timeframe and features}

RAE 2014 assesses institutions' research quality via three dimensions: research output, research grants and esteem measures. Among the three, "research output" was the heavy part of the equation, it constituted $80 \%$ of the total rating (University Grants Committee, 2013). The exercise covers research publications within a 6-year period ending at September 30, 2013. It assesses the research quality of the institutions on a sharpened basis by "cost centers" (not by individual researchers). Each "cost center" corresponds to one or more department or research center in an institution.

The UGC specified that research output submitted must meet all 3 criteria: containing an element of innovation; contributing to scholarship; and being publicly accessible. They can be publications, patents, artifacts published or made publicly available within the assessment period, or officially accepted for publication. They can also cover other formats, such as drama, buildings, or creative work that can be evaluated for merit and an assessment obtained. The UGC provided specifications on assigning doubleweighting, co-authorship, and other evaluation guidelines.

\section{Involving libraries in the early stage}

The reviewers were to view the documents in 2014. As early as 2011, the UGC invited representatives from the eight UGC-supported institutions to discuss the design and creation of an electronic repository. Representing HKUST, colleagues from the university's research office - Office of the Vice-President for Research \& Graduate Studies (VPRGO), and the Library attended these meetings. In these early meetings, spanning from November 2011 to May 2012, library representatives of various institutions contributed greatly to the discussion on options for electronic infrastructure, and on tackling the copyright issue of storing published items for reviewers' access. As a result of these preparatory discussion, the UGC planned to appoint an external developer to build an electronic system, named RAE Electronic System (RAEES), which was to centralize data from all institutions and to provide access interface for the reviewers. At the same time, individual institutions were required to build a document repository to host the institution's full-text files for reviewers' access. To resolve the copyright issue, librarians from all eight institutions joined hands. Working from the long-established collaborative platform - The Joint University Librarians Advisory Committee (JULAC), librarians worked to seek 
permission from publishers on one hand, and negotiated a transactional license with the copyright clearance agency -- Hong Kong Reprographic Rights Licensing Society (HKRRLS) on the other.

The active participation of librarians from HKUST and their constructive outcomes are elaborated in the next section.

\section{HKUST Library's participation in 3 stages}

\section{Design stage}

From late 2011 to mid-2012, the UGC involved all its funded-institutions to design the online system for the RAE 2014. HKUST Library's participation proved to be very instrumental.

The UGC expected to have a system that allowed institutions to make submission and at the same time let reviewers access the submitted documents seamlessly. At the beginning of the discussion, the UGC was completely open about the approach. Academic librarians in Hong Kong have ample experience in managing institutional repositories. At HKUST, we created and have been maintaining the fully open access HKUST Institutional Repository (IR) since 2003. In recent years we developed the Scholarly Publication Database (SPD) that integrates HKUST researchers' profiles and publications in one friendly interface. In this context, the HKUST IR, the SPD, and similar systems in other institutions provided solid operational models for the UGC's consideration. With our expertise in designing research information system, including the technical issues and copyright matters concerning depositing published work, librarians from HKUST contributed productively in this early planning.

\section{RAE Electronic System and Repositories}

After much discussion, the model as illustrated in Figure 1 was finalized. The UGC was to contract an external developer to build the RAE Electronic System (RAEES), to which institutions would submit lists and bibliographic metadata. The full-text research output files, however, were to be held in document repositories hosted and managed by each institution. The RAEES interface was to hold links for reviewers to access the research output in the document repositories. The UGC specified a token-based single sign-on interface between the RAEES and individual repositories. This allowed reviewers to transparently access any documents in all institutional repositories by using a single login at the RAEES.

At HKUST, in addition to the Document Repository that the UGC required each institution to build, we chose to develop an internal RAE platform for HKUST researchers and the cost center administrators to submit research output (RO); this platform is named RAE Online Submission System (ROSS). ROSS held all HKUST RAE data, which would be submitted to RAEES in one batch when all HKUST files were ready.

The Library was responsible for the creation of the Document Repository and the implementation of the single sign-on interface. Documents submitted by our researchers via ROSS were deposited in the Repository. 


\section{RAEES and Document Repositories}

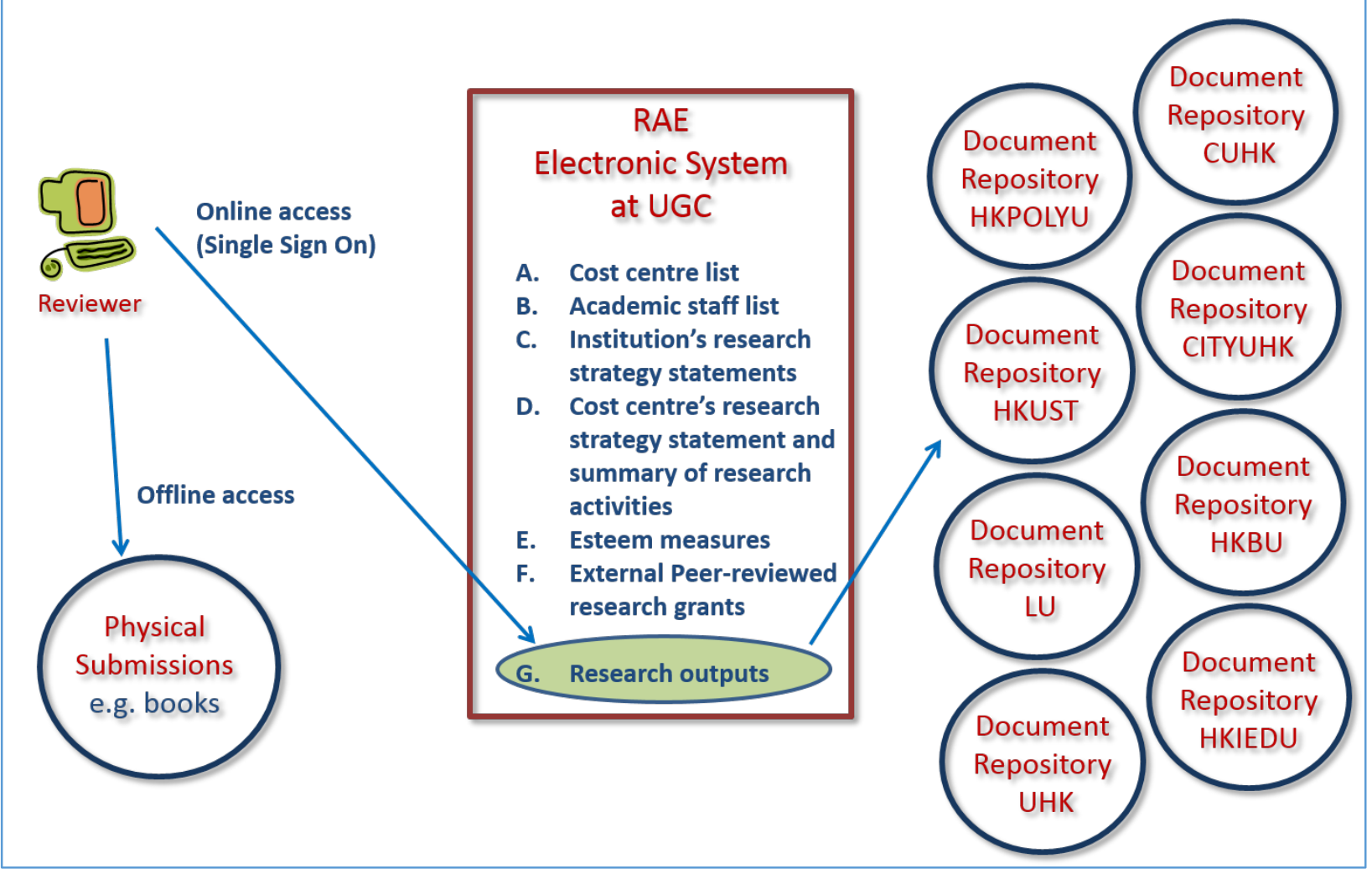

Figure 1. RAEES and document repositories

\section{Copyright permission or clearance}

From the first meeting called by the UGC in late 2011, all representatives from institutions raised concerned about the challenge of clearing copyright when creating repositories of research output for reviewers to access.

The idea of creating electronic repositories for the research output was partially modeled on the Australian Research Council's experience. However, in Australia, authorization was provided under Australian copyright law (Australian Research Council, 2011, pp. 68-69), a benefit Hong Kong lacks. Thus, the UGC and the universities eventually followed a clumsier, more tedious, and more expensive path.

After a lot of discussion, it was agreed that the UGC was to send out letters to "major publishers" identified by the institutions' libraries, seeking limited permission for use of copyrighted material for the RAE 2014. The libraries and the UGC collaborated on creating the template letter in fall and winter 2012. An HKUST librarian and the JULAC Manager volunteered as the contact point for publishers' queries and follow-up; they coordinated between the UGC and the 140 publishers, recorded and posted answers for all institutions from December 2012 through spring 2013. 
At the same time, knowing that not all publishers would agree to give free permission for the project, the JULAC Copyright Committee (JCC) negotiated with the Hong Kong Reprographic Rights Licensing Society (HKRRLS) from summer through winter 2012 to work out a process, which resulted as a transactional license, for clearing copyright of those items not granted publisher permission.

Apart from the 140 "major publishers" whom the UGC contacted with the help of JULAC, there were many other publishers whose publications got selected by researchers for RAE 2014. The JCC drew up guidelines and processes for individual libraries, for contacting these so-called "minor publishers" for non-fee permission to use their materials on behalf of the eight UGC institutions, and then recording their answers in a file shared by all libraries. This work was accomplished from late spring until the end of 2013. Ultimately 1,373 publishers were contacted, 63 by HKUST.

At HKUST, we custom-made the Document Repository filing structure to facilitate the copyright processing. Documents in the Repository were grouped according to their copyright permission categories, which were: a) Self-archiving, b) Permission without charge, c) Permission without charge but must listed, d) Permission with charge and e) Transactional license. After the review in 2014, we were to compile access reports based on this grouping. In particular, to calculate the total license fee for the transactional license, we were required by HKRRLS to send a final list of documents covered, with detail information about the number of reviewers accessing the documents, the total number of times accessed, and the number of pages of each document. Our grouping design greatly simplifies the compilation of such lists.

Overall speaking, enormous amounts of time and effort were spent on dealing with the copyright issues. In working through the complexities of clearing copyright for the research output, individual libraries and the academic library community in Hong Kong via JULAC were able to show the UGC and university administrators their valuable knowledge and expertise.

\section{Forming project teams at HKUST}

In mid-2012, HKUST formally formed groups at different levels to manage the process of submission for the RAE 2014:

- At the highest level was the RAE Task Force. It was led by the Vice-President for Research and Graduate Studies. Other members included the associate deans of each school, representatives from the Provost's Office and Grants Office, and the University Librarian.

- A separate Working Group involved administrators of each school. The Associate University Librarian represented the Library in this group.

- The RAE team, led by the Senior Advisor from VPRGO, managed and oversaw the whole RAE preparation and submission process as well as developed the HKUST submission interface ROSS. The Senior Advisor was the key person directing the collaborative effort.

- The Library team was responsible for handling the research output data: obtaining full-text of electronic copies, clearing copyright, verifying metadata, and developing the Document Repository. It also assisted the RAE team in developing ROSS. 
- The university's Information Technology Services Center (ITSC) and the Joint Universities Computer Centre (JUCC) were later involved to ensure that institutions' repositories were robust enough for reviewers to access smoothly.

Many parties and many people participated in the project, each carried its own roles, perspectives, priorities and expertise. Figure 2 visualizes how the HKUST teams worked with each other and with nonHKUST parties.

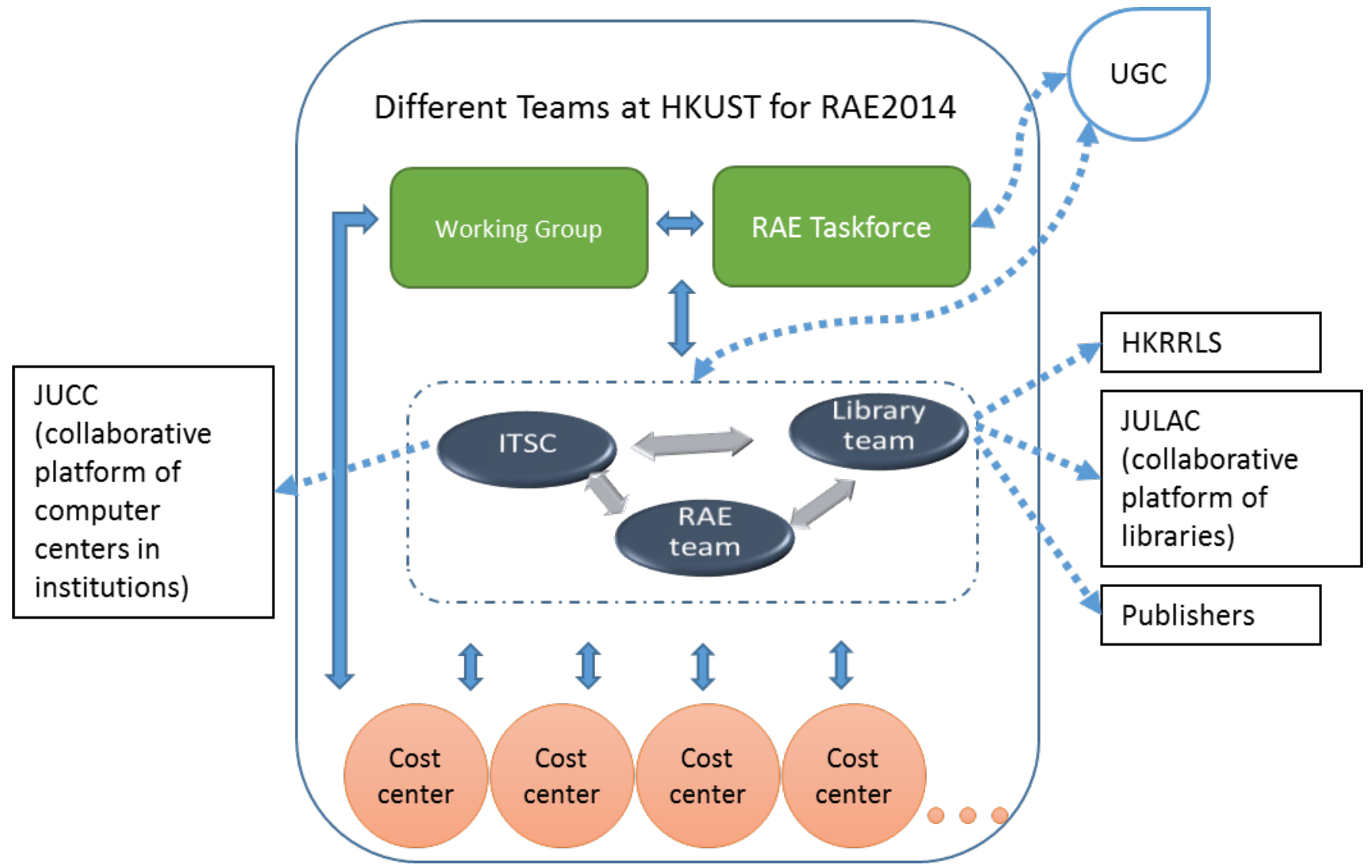

Figure 2: Working relation between teams at HKUST

\section{Formation stage}

In late 2012, the Library pulled together librarians from different units to plan for the RO processing. Two librarians had already been active in the discussion with the UGC during the design stage, one with technology and database expertise, one was knowledgeable in the area of copyright. In addition, we enlisted colleagues from cataloguing, scholarly communication, document delivery and acquisitions, for their expertise in such areas.

Once formed, the team commenced to identify potential issues and work out workflow. At the same time, the University Librarian kept close communication with the RAE Task Force at the university level. She conveyed to the team the Roadmap set by the Task Force to guide our work; she envisioned resources required for the processing, and put through requests for additional resources. 
ROSS was constructed by the RAE team led by VPRGO, and the Library played a significant role in its design and testing, particularly in the modules for researcher submission and library operations. By making use of an API that the Library developed, researchers could select research output from the Scholarly Publications Database (SPD); the selected metadata would be automatically fed to ROSS. This greatly helped to reduce researchers' input effort and to standardize the data format.

\section{RAE "Dry Run" and ROSS training for cost centers}

In early 2013, the University RAE Task Force advised cost centers to perform a mock-up exercise, labelled "Dry Run", to select the research output, coordinate co-authored submission, and review internally the research output and esteem measures. Around the same time, ROSS was ready for pilot use. The Library helped to organize and host hands-on training sessions for cost centers. Two rounds of workshops were held. In the first round in late January 2013, around 40 representatives from the cost centers attended two workshops. As a step forward, four tutorial sessions were held during mid to late April to provide faculty members and cost center administrators with hands-on experiences of using ROSS. During those sessions, on-the-spot technical support was offered once the participants encountered any problems in data input. In total, around 45 colleagues joined the sessions.

At the end of the Dry Run, Library staff used the data to test run the workflow with each processing step. The Dry Run turned out to be a crucial exercise that revealed submission issues for cost centers, technical issues for the ROSS developer, and bibliographic and workflow issues for the Library team.

\section{Data processing stage}

The Library's participation in RAE data submission focused on the processing of research output. In spring and summer of 2013, while ROSS entered its production phase, and individual cost centers finished their Dry Run and internal review one after another, data input started to pick up steam. All RO data were to be processed by the Library team, which was subdivided into Full text team, Metadata team and Copyright team. There were 19 cost centers at HKUST, each of them submitted their RO data in batches. Effective coordination between the Library, VPRGO and cost centers became the key to facilitate efficient and timely processing.

\section{Roles of cost centers in RO data preparation}

After several rounds of discussion and workflow testing, the RO processing logistics between the Library and cost centers were decided as such:

1. Cost center administrators coordinated with their eligible researchers to select the RO to be submitted

2. Cost center administrators entered the data into ROSS, filled in as many data fields as possible; and attached the full-text PDF files of the RO if available

3. When a cost center completed all their data input, the administrator informed the RAE team and the Library team; the latter was to check the data in batches in ROSS, center by center

4. The Library team verified the eligibility of the RO, the metadata and the full-text version. Problems identified were conveyed to and resolved with the corresponding cost center administrators or researchers

5. After the whole batch for a cost center was verified, the Library informed the cost center for further action and final proofing 


\section{Library workflow}

A batch of RO typically went through this flow:

1. Full-text team - verified the citations of each RO, ensured that the proper full-text PDF files were in place.

2. Metadata team - checked all data fields of each RO, ensured that all supplementary documents were submitted.

3. Copyright team - checked the copyright category of each RO, marked it for copyright clearance as appropriate.

\section{Full-text Team}

The team, led by the Document Supply Service librarian, checked the eligibility of the RO and obtained the proper and quality full-text files. The colleagues in this team have substantial experience, knowledge and tools to verify citations, locate sources, and obtain copies. They were the gate-keeper who screened problematic submissions, hence helped cost centers to rectify cases early in the process, and improved efficiency of subsequent library workflow.

\section{Metadata Team}

The responsibilities of the team were to verify and input metadata of RO; and to ensure all supplementary documents were in place. In addition, for RO to be submitted in physical formats (e.g. published books), the team obtained physical copies and handled subsequent processing such as labelling and packing following the UGC's requirements.

RO came in different types, ranging from journal articles, book chapters, conference papers, books, working papers to music compositions; each type led to a variety of requirements on metadata. Most RO records contained 17 data fields; double-weighted ones had 34 fields. The Metadata team, composed of colleagues from Cataloging and Acquisitions, did a meticulous job to ensure the accuracy and completeness of all the RO data.

\section{Copyright Team}

The Copyright Team categorized RO by the types of copyright status. The team kept the records of publishers' replies, and recorded RO that required clearance through the transactional license.

\section{Communication with cost centers}

To manage the submission progress of 19 cost centers, and to resolve with them various RO issues that the Library team identified during the process, effective and timely communication was very crucial. VPRGO created an internal website to post RAE-related information. The Library made use of this site to post a webpage that tracked the progress of each cost center. The page kept every party informed, and gave realistic timeframe for cost centers to schedule their submission for Library's processing.

Apart from online communication, from July to September of 2013, the Senior Advisor scheduled individual meetings with cost centers to communicate, clarify, and seek to resolve, any submission problems. The Library team used this face-to-face opportunity to report the statistics of RO submission, 
and to clarify any complex, outstanding RO issues with individual cost centers. These meetings were very effective in speeding up the submission progress.

\section{Developing computer programs to facilitate Library processing}

ROSS contained close to 2,000 RO records, each carried a score or more data fields, handled by multiple personnel at the cost centers or the Library team. To ensure data quality and processing integrity, a systems colleague in the Library team created various computer programs to perform tasks such as generating daily status reports, detecting invalid characters, synchronizing or validating PDF files, and more.

\section{Load tests for document repositories}

In mid-2013, the UGC began involving the Joint Universities Computer Centre (JUCC) in soliciting their expertise to make sure that document repositories hosted by individual institutions were configured with required network bandwidth and access speed performance. The UGC was mindful to assure that reviewers would be able to download the documents at reasonable speed, and that the document repositories could serve sufficiently high number of concurrent users. JUCC assigned the Information Technology Services Center of HKUST (ITSC) to design and conduct load tests on the repositories. The Library was active in providing suggestions to ITSC in the design. Modeling along the Library's internal testing method on our Document Repository, ITSC came up with a design, involving automated agents locating on the network in the USA, UK, Australia and HARNET (Hong Kong Academic and Research Network) simulating simultaneous downloading of documents. Two rounds of load tests were conducted in late 2013. They were very useful in identifying loading issues of some of the document repositories.

\section{Submitting to RAEES}

After rounds of data inputting, library checking and cost center checking, the set of HKUST data was eventually ready to be uploaded from ROSS to the UGC RAEES. HKUST had 1,623 research output together with many files detailing research grants and esteem measures. However, the Library in fact processed more than 1,800 records, since some RO submitted did not comply with the UGC's requirements, while some processed records were later replaced by the researchers and therefore required new processing.

The official submission was held on December 16, 2013 as a ceremonial event in the Library's Special Collection Gallery. The Vice-President of Research and Graduate Studies, the Senior Advisor, together with key members of the RAE team and the Library team, triggered the data submission from ROSS to RAEES.

The Library's work did not end at this submission. After the reviewers performed their reviewing in 2014, each institution was to pay for the copyright clearance via the transactional license. At HKUST, this follow-up work was to be performed by the Library also.

\section{Challenges faced by the Library}

\section{Resolving the copyright issue}

The Copyright Ordinance of Hong Kong does not cover the use of copyrighted publications in RAEs. The UGC did not have prior arrangement with publishers to allow using their publications this purpose. As a 
consequence, librarians and the UGC had to work out ways to negotiate with a large number of publishers and with the copyright clearance agency HKRRLS. Tremendous amount of effort was put into the project to handle the copyright issue.

\section{Meeting the submission requirements}

As the project schedule was very tight, the system requirements and the data submission guidelines for RAEES were not well specified in advance. Often some guidelines were still being finalized on the UGC side while the related work were already in progress at HKUST.

Moreover, the data requirements were rather complex, and at times unclear or incomplete. Librarians from the UGC-funded institutions helped out in clarifying and giving feedbacks to the UGC and the RAEES developer. In particular, the Metadata team at HKUST Library made a few suggestions on the metadata specifications; these suggestions were well-received and accepted by the UGC.

\section{Locating or purchasing RO}

Apart from electronic submission, some RO had to be submitted to the UGC in physical format. Sourcing the physical items was a challenge as they came in different formats, languages and publication years. Some older ones were difficult to get as they went out-of-print, or out-of-stock.

Some conference papers were difficult to locate. Some were never published, some were no longer available online as the conference websites were changed. The Library team worked with the researchers case-by-case to locate accessible copies that comply with the UGC's requirements.

\section{Helping cost centers resolving problematic RO}

The Library workflow essentially assisted the cost centers and the researchers to make sure their selections of RO met the UGC's requirements. Problematic cases arose usually when a publication was in-press, or not publicly available due to various reasons. To resolve such cases with them, the Library team often had to apply terms and concepts such as "pre-published version", "articles in press" and "self-archiving", which were not trivial for non-library personnel. Academic publishing is changing rapidly with new technologies and publishing models. It was a challenge even for researchers to distinguish different stages of article publication. The Library team had to be extra skillful in communicating with the cost centers administrators when sorting out problems.

\section{Commendation and Appreciation to the Library}

The Library's contributions and effort in the project were widely recognized by the parties involved. We received very positive comments and notes of appreciation from the university administrators, staff of VPRGO and cost centers. They saw the values that the Library has put in the whole process.

The project helped the Library to raise the university's awareness to the value of the research information management developed by the Library. In particular, the HKUST Scholarly Publications Database (SPD) had enjoyed higher access during the project. As SPD facilitated the transferring of metadata into ROSS, researchers reviewed their scholar profiles and publication lists in SPD when selecting their RO; they were more motivated to report errors and missing items. SPD attracted enough attention that the university added a link to it at the university website for searching scholarly publications of HKUST faculty and researchers. 


\section{The Keys to Success}

In retrospect, the success of the Library's contributions to RAE 2014 can be attributed to the followings:

\section{Proactive leadership}

At the university level, this preparation work for RAE 2014 was steered and supervised by the specially appointed Senior Advisor, who led the RAE team to closely monitor the whole process, key tasks, progress, and timeline. Being the former Dean of the Graduate School at HKUST, he benefited the project with his excellent management skills and rich experiences. He liaised with deans, department heads, faculty and cost center administrators to get submissions done on time and as scheduled. He identified problems, clarified issues, cleared obstacles and advised on hindrances. His effective leadership facilitated the success of the Library's effort.

The Library took leadership in our areas of expertise. At the design stage, we actively located potential issues. We offered advices for the electronic infrastructure and copyright clearance pathways. Working with other teams within HKUST, we engaged in different stages in designing and modifying ROSS. Librarians led the discussion and took action on copyrights and licensing issues with the UGC and HKRRLS. We were proactive in tackling challenges in obtaining full-text, clearing copyright, verifying metadata, creating document repository, and purchasing physical items. The Metadata librarian advised the RAEES developer on data field formats. Instead of holding back and reserving our resources, the Library reached out to contribute and comment. Positive outcomes established the Library's credibility.

\section{Motivated professionals}

The Library team comprised of librarians and technical staff with knowledge in network infrastructure, programming, cataloging, document retrieval, copyright and intellectual property. Staff were given high level of autonomy, clear expectation and trust to do their parts. Frequent meetings were held to plan for internal workflow, monitor progress, report problems, find solutions, and formulate next steps. Professional librarians mobilized support staff in their own units and recruited student helpers to manage the workload. It was a big and highly spirited team.

At the same time, librarians' professional expertise in creating metadata and database was well demonstrated. Our knowledge in the trends of scholarly publishing and contacts with publishers allowed us to play an important liaison role in dealing with copyright and licensing issues.

\section{Effective communications}

Timely and effective communication was crucial as the project involved so many parties. The University Librarian was a member of the University's RAE Task Force. She brought back news and demands to the Library team, which in turn met with the RAE team often for operational issues. Communications, progress and FAQs were listed through the university's internal website. Library team set up internal web manual to document information, policies, and guidelines. Two team members served as liaison persons between the Library and all cost centers to track progress. We set up a designated email account for cost centers to send us any RAE questions. For special cases, such as one researcher who 
was to upload audio-visual research output that called for special treatment, librarians arranged special meetings with him to sort out the issues.

\section{Flexibility and creativity}

For project of this scale, uncertainties are unavoidable. During the process, the Library team always tried to plan ahead as much as possible, and at the same time maintained the flexibility to modify the plans if necessary. For example, a few times the UGC guidelines on some data requirements were ambiguous; we asked for clarifications, which took weeks to come back. During this time our process continued with workflow modification in such a way that the affected fields did not hinder the progress.

\section{Project and resource planning}

Early planning helped the project started smoothly on the Library side. As soon as enough directions were given from the UGC and the university administrators, the Library visualized the operations and corresponding tasks, which were laid out in flow charts. At the same time, the University Librarian estimated a budget on manpower required (essentially student helpers), copyright clearance, buying full-text articles, and ordering copies of books for physical submission. She submitted this budget to VPRGO promptly and got approved. It enabled a smooth transition for the Library team when the workload turned heavy as the project progressed.

\section{Summary}

The Research Assessment Exercise 2014 was a high-stake exercise for the publicly-funded institutions in Hong Kong, as the assessment result imposes implication to future research funding. To showcase the research quality, each institution put in a good amount of resources to select the best research output and to highlight other research parameters. For RAE 2014, additional challenge in operational aspect was laid as the exercise was to be conducted completely online. This challenge turned out to be an interesting opportunity for university libraries to demonstrate their expertise in research information system, including building databases, managing metadata, and handling copyright issues of published output.

At HKUST, the Library proactively participated throughout the whole process. Based on our experience of operating the Institutional Repository and the Scholarly Publication Database, we offered suggestions, ideas and feedbacks at all levels; we assisted other parties in system design and problem solving; we selflessly put in human resources to create the database of research output with good quality control; we communicated well with all parties to ease the complexity of the tasks for non-library colleagues. As a result of all these efforts, the HKUST research community now perceives the value of the Library's research information management system, including the IR and the SPD; and has more trust on librarians' expertise in providing research support service. 
This is the Pre-Published Version

Actively Demonstrating Library Expertise in a Research Assessment Exercise

\section{Bibliography}

Australian Research Council, 2011. ERA 2012 Submission Guidelines, Canberra: s.n.

Haddow, G., 2012. Research Support in a Research Assessment Environment: the experience of 'new' universities. Library and Information Research, 36(11), pp. 62-80.

Housewright, R., Sconfield, R. C. \& Wulfson, K., 2012. Ithaka S+R US Faculty Survey, New York: ITHAKA.

Key Perspectives Ltd. for OCLC Research, 2009. A Comparative Review of Research Assessment Regimes in Five Countries and the Role of Libraries in the Research Assessment Process, Dublin, OH: OCLC

Research.

MacColl, J. \& Jubb, M., 2011. Supporting Reserach: Environments, Administration and Libraries, Dublin, $\mathrm{OH}$ : OCLC Research.

University Grants Committee, 2013. RAE 2014 Guidance Notes (May 2013). [Online]

Available at: http://www.ugc.edu.hk/eng/doc/ugc/rae/gn 201305.pdf

[Accessed 10 August 2014]. 